\title{
REPRESENTAÇÕES DE GESTANTES ADOLESCENTES SOLTEIRAS SOBRE ASPECTOS DE SUA PROBLEMĀTICA PSICOSSOCIAL
}

\author{
Telma Ribeiro Garcia ${ }^{1}$
}

GARCIA, T.R. Representações de gestantes adolescentes solteiras sobre aspectos de sua problemática psicossocial. Rev. Bras. Enf., Brasília, 38(3/4): 281-288, jul./ dez. 1985.

RESUMO. Estudou-se um grupo de oito gestantes adolescentes solteiras, com idade entre 15 a 18 anos, que compareceram ao Serviço de Pré-Natal de uma instituição localizada no Município de São Paulo, entre janeiro a junho de 1984. O objetivo foi o de conhecer as representações dessas gestantes sobre aspectos de sua problemática psicossocial. 0 método utilizado foi o qualitativo. $O$ conhecimento das representações dessas gestantes e a análise resultante da interpretação de seu discurso evidenciaram o desajuste psicossocial para o qual a gestação em adolescentes solteiras pode concorrer.

ABSTRACT. A group of eight unmarried pregnant teenagers with ages between 15 and 18 was studied at the Prenatal Service of a São Paulo institution. The work aimed at learning how they represent some aspects of their own psychosocial problems. The method used was the qualitative one. These pregnants representations and the interpretative analysis of their discourses evinced the psychosocial inadaptation for which the teenager unmarried pregnancy could contribute.

\section{INTRODUÇÃO}

A gestação na adolescência representa uma superposição de crises vitais: uma evolutiva, a adolescência, que se caracteriza por uma transição gradativa de um organismo infantil para um organismo adulto, com reflexos somáticos e psíquicos, decorrentes principalmente das alterações que ocorrem na esfera sexual (VALENTE et alii) ${ }^{6}$, e outra situacional, a gravidez, tipo de crise que independe da idade devido às perspectivas de mudança de papel social, necessidade de novas adaptações, reajustamentos interpessoais e intrapsíquicos e mudança de identidade (MALDONADO) ${ }^{3}$.

Ora, quando à crise da adolescência se acrescentam as tensões da gravidez, é de se supor, como afirmam CAMPOS \& CARVALHO ${ }^{1}$, que o fardo se torne excessivamente pesado, principalmente se a gravidez ocorre fora do casamento. Segundo SIL
$\mathrm{VA}^{5}$ e CLAMAN et alii ${ }^{2}$, é fácil imaginar o desespero, o medo e a insegurança de uma adolescente solteira ao descobrir que está grávida.

Neste trabalho, procurou-se conhecer, mais de perto, a realidade concreta da gestante adolescente solteira, considerando-se o fenômeno biológico de sua gestação integrado aos aspectos psicossociais que aí intervêm, integração a que se atribui fundamental importância na tarefa de subsidiar a assistência que cabe à enfermeira obstétrica.

Ao se procurar conhecer a realidade concreta da gestante adolescente solteira, o que se buscou foi apreender o fenômeno da gestação na adolescência sob o ponto de vista do próprio sujeito, ou seja, descobrir que significados a gestante adolescente solteira atribui aos fatos, às situações, aos acontecimentos, às pessoas que a cercam e às suas próprias ações.

O trabalho, assim, visou estudar a problemá-

1 Mestre em Enfermagem Obstétrica e Neonatal. Professor Assistente IV do Departamento de Ciências da Saúde/Curso de Enfermagem da Universidade Federal do Acre. 
tica psicossocial da gestante adolescente solteira não sob o ponto de vista explicativo-causal, mas do ponto de vista compreensivo, no qual a gestante se apresenta como se afirmasse: "Eu sou eu, minha gestação e minhas circunstâncias". Desta forma, cada gesto, atitude, preocupação, queixa, cada sentimento ou idéia tem um significado que só pode ser avaliado em função do ser histórico-social que a gestante adolescente solteira é.

Acredita-se que é somente a partir dessa compreensão que pode ser estabelecido, entre a enfermeira obstétrica e a gestante adolescente solteira, um relacionamento interpessoal significativo, no âmbito do qual a profissional, considerando a historicidade da adolescente e o próprio processo de relacionamento interpessoal como fontes de dados para sua ação, tenha oportunidade de ajudar a adolescente a conviver com a situação-problema vivenciada no momento, ao mesmo tempo em que lhe presta uma assistência de enfermagem voltada para $o$ indivíduo enquanto unidade bio-psico-social indivisível.

Portanto, o objetivo deste trabalho foi conhecer as representações de um grupo de gestantes adolescentes solteiras sobre aspectos de sua problemática psicossocial.

\section{MATERIAL E MÉTODO}

A população do estudo foi constituída por primigestas, na faixa etária de doze a dezoito anos (adolescentes), com idade gestacional igual ou superior a vinte semanas, e que compareceram, de janeiru a junho de 1984, durante o período matutino, ao Serviço de Pré-Natal da instituição escolhida.

A escolha desta instituição foi determinada pelo critério numérico: trata-se de uma instituição para onde converge a grande maioria das mães solteiras do município de São Paulo, o que facilitou o contato com a população estudada.

No desenvolvimento do trabalho podem-se distinguir três fases.

$\mathrm{Na}$ primeira fase, que ocorreu durante os meses de novembro e dezembro de 1983, compareceu-se diariamente ao Serviço de Pré-Natal, com a finalidade de facilitar a inserção na rotina de atendimento da instituição e tornar-se conhecida por aqueles que, direta ou indiretamente, participam desse atendimento. Para alcançar este fim, procurou-se atender a qualquer gestante que se apresentasse, independentemente de idade, estado civil ou idade gestacional, realizando-se tanto primeiras consultas como consultas subseqüentes, ou de retorno.

$\mathrm{Na}$ segunda fase, que se desenrolou em janeiro de 1984, procurou-se centrar o atendimento na população do estudo. Nesta etapa, foram realizadas doze primeiras consultas com gestantes adolescentes, ainda independentemente do estado civil e da idade gestacional. Com isto, tinha-se por finalidade verificar até que ponto sua problemática correspondia à idéia pré-formada a partir das leituras sobre o assunto, e testar qual a melhor forma de abordá-las para a obtenção dos dados que se procurava para o estudo.

$O$ roteiro que inicialmente havia sido elaborado para as entrevistas sof reu alterações durante esta fase. Observou-se que muitas das perguntas originalmente contidas no roteiro poderiam produzir respostas mais abrangentes se fossem formuladas como perguntas abertas. Chegou-se então à conclusão de que a melhor forma de abordar o assunto seria solicitar que a gestante falasse sobre sua vida, sua família e seu namorado. A partir daí - e se em seu discurso não estivessem contidas -, introduzir-se-iam as questões da ocorrência da gestação, dos seus sentimentos quando soube da gravidez, do que aconteceu quando a família e o namorado souberam da gravidez, dos seus planos com relação à criança e de suas expectativas futuras para si própria, de suas ansiedades e do tipo de ajuda que considerava necessária no momento.

A terceira fase, a do estudo propriamente dito, teve seu início no final do mês de janeiro de 1984, prolongando-se até meados de junho do mesmo ano.

A identificação das gestantes que tomariam parte do estudo foi feita no próprio local de aten. dimento pré-natal, contando-se não só com a ajuda de enfermeira responsável pelo turno da manhã, como também com a colaboração de estagiários do Serviço Social a quem se havia explicado o tipo de trabalho que se estava desenvolvendo e os critérios que se haviam estabelecido para selecionar as unidades amostrais.

Pretendia-se que a apreensão da problemática psicossocial da gestante adolescente solteira se realizasse a partir de suas representações sobre a realidade que vivenciava, e que essa apreensão surgisse por meio de contatos semi-estruturados e sucessivos, devendo cada contato assumir a forma de uma entrevista aberta. A estratégia que se utilizou para a ocorrência dos encontros foi a de realizar a assis- 
tência pré-natal das gestantes que eram selecionadas para o trabalho.

Uma vez identificada, realizava-se a primeira consulta pré-natal da gestante adolescente solteira e, neste primeiro contato, procurava-se colocá-la a par da natureza do estudo que se desenvolvia e de seus objetivos, garantia-se o anonimato em que os dados seriam apresentados e procurava-se obter o seu consentimento para participar dele. Obtido o consentimento, solicitava-se sua permissão para gravar a entrevista.

As entrevistas foram realizadas com base em dois procedimentos. No primeiro contato, a entrevista era de maior duração - em média uma hora e meia para cada gestante - e, nessa ocasião, utilizava-se o gravador. Nos contatos subseqüentes, os dados complementares à primeira entrevista eram anotados após o encontro.

Ao final de cada primeiro encontro, solicitava-se às gestantes que fizessem uma avaliação da entrevista. São exemplos dessas avaliações o que se segue:

"Achei bom, assim eu já me desabafei. Foi um pouco dificil contar essas coisas mas, guardar tudo não pode, né?"

"Essa entrevista pra mim foi como um desabafo. Na verdade, eu não costumo sentar assim na frente de uma pessoa e falar tudo que eu sinto, tudo o que se passou comigo, o que continua se passando. Essa entrevista para mim foi como um desabafo. Como um peso que tirẹ da consciência, né? Coisa que eu nunca fiz antes, sentar assim e falar de minha vida... E isso ai!"

Em decorrência do método que se elegeu para a abordagem do trabalho, não se tinha previsto um número amostral determinado. As gestantes foram sendo selecionadas à medida que se apresentavam ao Serviço de Pré-Natal, e o número de participantes foi delimitado durante o próprio processo de pesquisa, quando se começou a notar que as histórias de vida estavam se repetindo e que um número maior de gestantes não acrescentaria muito aos dados que já se havia obtido.

Para a apresentação dos resultados, as informações obtidas do discurso das gestantes adolescentes solteiras foram submetidas a uma descrição do tipo qualitativo, utilizando-se para tanto o discurso das gestantes em linguagem original.

Vale a pena ressaltar que se considera pratica- mente impossível apreender toda a problemática psicossocial da gestante adolescente solteira de uma só vez. $O$ estudo se limita, portanto, a apresentar uma descrição de aspectos selecionados des. ta problemática. Sob o ponto de vista da metodo. logia utilizada, sua importância reside exatamente na possibilidade de propiciar à Enfermagem uma maneira de encarar o problema dif erente das usuais, e de os seus resultados levarem outros a refletir sobre 0 assunto de forma a gerar novas práticas.

\section{RESULTADOS E COMENTÅRIOS}

Durante a fase de planejamento, determinou-se para o trabalho a inclusão de gestantes adolescentes solteiras na faixa etária compreendida entre 12 a 18 anos. No espaço de tempo que se destinou à seleção das participantes, no entanto, não ocorreu o comparecimento, ao Serviço de Pré-Natal, de gestantes com idade inferior a 15 anos, ficando o estudo restrito à participação de gestantes com idade de 15 a 18 anos.

De uma forma geral, as gestantes deste estudo são moças provenientes de famílias de baixo poder aquisitivo, e a necessidade de ajudar na renda familiar foi o motivo mais freqüentemente citado para o abandono dos estudos. A média de tempo de escolaridade era de quatro anos e, segundo afirmaram, o abandono da escola precedeu, em muito, a ocorrência da gravidez. Uma afirmou nunca haver freqüentado a escola.

A ocupação principal relatada foi a de empregada doméstica embora, na ocasião em que os dados foram coletados, nenhuma estivesse trabalhando, mesmo porque "grávida elas não aceita" como informou uma delas.

Em relação ao background familiar, constatou-se que os lares desfeitos e a ausência de figuras parentajs estavam presentes na narrativa de cinco das gestantes estudadas. Notou-se que o padrão predominante da interação de algumas adolescentes com os familiares traduzia-se por relações autoritárias e dominadoras, principalmente no que diz respeito às relações dos elementos do sexo masculino com elas. $\mathrm{O}$ estudo, no entanto, não alcançou um aprofundamento suficiente para que se proponha estas interações como explicativas do evento da gestação nas adolescentes. Nem era esta a intenção. Ao se questionar a gestante adolescente solteira sobre seu relacionamento com os familiares, pretendia-se compreender como este relacionamento poderia influir sobre suas reações com rela- 
ção à gravidez e sobre as resoluções que tinha tomado ou estava tomando.

0 problema da gestação em adolescentes, especialmente quando solteiras, é muito complexo, não podendo a gestação ser definida como resultante deste ou daquele fator isolado, ou como tendo esta ou aquela conseqüência específica, quer individual, familiar ou social.

No entender da autora, se a gravidez destas adolescentes for encarada primariamente como um sintoma de patologia emocional básica, provavelmente grande parte de seu comportamento poderá ser visto em termos similares, confirmando-se esta hipótese. Por outro lado, encará-la apenas como resultado de exercício inconseqüente da sexualidade, ou do desconhecimento ou uso inadequado de métodos anticoncepcionais, não parece ser satisfatório para a compreensão do fato. Também as interações adolescentes/familiares não devem ser, por seu turno, consideradas as únicas responsáveis pela ocorrência da gravidez.

Para uma melhor compreensão, deve-se ter em mente a realidade concreta destas gestantes - realidade historicamente determinada e de onde avulta a questão das condições em que se dá, em nossa sociedade, a socialização dạ mulher; em que ela constrói e é reforçada a sua identidade social/ sexual.

Pelos resultados que se obteve neste estudo, a atividade sexual pode ser iniciada por uma adolescente como uma maneira de comprovar as acusações de familiares neste sentido, sendo necessário "fumar bastante e beber bastante" antes que ocorra à relação sexual (conforme o relato de uma delas); pode ser iniciada, também, por uma aparente inabilidade para resistir a persuasão do namorado: "Ele me chamou... eu fui"; ou como conseqüência natural do envolvimento emocional com o namorado.

É importante que se ressalte que algumas nunca receberam qualquer informação sobre sexualidade e reprodução humanas:

"Quando aconteceu, eu me senti estranha porque... eu não sabia o que era aquilo. Nunca tinha fazido aquilo. Eu não sabia o que é que era... Depois, ele me contou. Ele falou pra mim que era uma coisa que se chamava transar. Eu era mofa... não sabia o que era aquilo".

Não se pode afirmar, no entanto, que elas não terıham recebido educação sexual, pois expressaram valores relativos ao sexo e à sexualidade que, seguramente, lhes foram transmitidos durante $o$ processo de socialização. Em função das proibições a respeito do sexo e da negação de suas manifestações, que marcam o meio em que vivem, as adolescentes incorporam a idéia de que o sexo e a sexualidade são algo perigoso, cuja prática as sujeita a castigos físicos ou morais.

Quer vejam a si mesmas como vítimas das intenções pouco escrupulosas dos namorados, quer tenham iniciado a atividade sexual de forma consciente, vale ressaltar a posição destas adolescentes em relação ao sexo pré-conjugal. Sujeitas a um código sexual ao qual nem sempre aderem, observa-se que esta posição pode variar de um raciocício do tipo:

"É uma coisa tão comum hoje em dia, né? Pelo menos... a mulher, assim, mais liberal... que já transa antes do casamento e tudo, né?

a uma nítida divergência entre suas palavras e seus atos, o que reflete a contradição da moral sexual prevalente em quase todos os segmentos da nossa sociedade. Esta contradição é expressa, de um lado, através da aparente liberalização de padrões de comportamento e valores relativos à sexualidade e, de outro, através de ações repressivas como, por exemplo, o padrão de "sexo-medo" inerente à educação sexual tradicional considerada como uma das soluções possíveis para o controle da proliferaçđo das doenças sexualmente transmissiveis, do aborto e do nascimento de filhos ilegítimos.

Ainda persistem restrições sociais tradicionais para aqueles que se aventuram a exercer livremente sua sexualidade; as normas socio-culturais prevalentes afirmam e negam, a um só tempo, o direito do individuo ao exercício de sua sexualidade:

"Eu acho que é ruim porque... escondido, assim, se pega uma gravidez antes do casamento né? Mas, eu não tava nem ai. Agora, que a senhora perguntou pra mim, é que eu tô falando. Eu acho que não tá certo, não".

A questão da atitude em relação ao sexo pré-conjugal remete à do conhecimento e uso de métodos contraceptivos. Quase todas as adolescentes do estudo conheciam métodos anticoncepcionais, principalmente o anticoncepcional oral. Uma delas relatou que, após iniciar as relações sexuais com o namorado, tomava três comprimidos anticoncepcionais pela manhã e três à noite; outra relatou que conhecia mas não tinha usado o anticoncepcional oral porque a mãe, que usava, "tinha ficado com infecção na bexiga e teve que ser operada" - ela tinha medo que o mesmo acontecesse com ela e 
por isso não tinha usado; outra informou que teve medo de perguntar para alguém sobre como evitar a gravidez e esse alguém ir contar para os familiares que ela estava mantendo relações sexuais com o namorado.

Sobre esta questão, considera-se básico que se questione: a) já que as adolescentes têm livre acesso à aquisição de anticoncepcionais, não deveriam, também, ter acesso à orientação e acompanhamento de uso destes medicamentos? b) não é contraditório que uma jovem receba constantes estímulos para exercitar sua sexualidade e não possa admitir esse exercício por temor de castigos físicos ou mo. rais?

Ainda sobre a contracepção, é necessário que se enfatize o papel e a responsabilidade do indivíduo do sexo masculino em prevenir gestações indesejadas. Deve-se considerar, a esse respeito, que se espera que a mulher deva "se cuidar" não somente do assédio erótico do homem, como, também, da possibilidade de uma gravidez vir a acontecer. Assim, a nível do cotidiano, o problema é motivo de debates acalorados, sendo as expectativas sociais dos papéis masculino e feminino o principal foco de discussão.

No estudo, apenas uma adolescente referiu-se ao uso de métodos anticoncepcionais pelo namorado. Veja-se como:

"... ele usava um negócio, né? Depois parou de usar. Ele usava um negócio de plástico. Ele não usou da primeira vez, na segunda também não, nem na terceira. Foi na quarta vez que ele usou. Depois, ele esqueceu de comprar e não usou. A i não desceu mais."

Assim, as adolescentes se vêem diante da realidade de uma gestação.

As manifestações emocionais da gravidez mostram um desenrolar dinâmico durante seu curso. Assim como é importante, ao falar sobre o estado físico da mulher grávida, especificar o estágio de sua gravidez, também deve ser tido em mente o mesmo escuema quando se procura entender o seu comportamento e reações com relação à gravidez.

O impacto da gravidez, anunciando mudanças no funcionamento psicofisiológico da mulher e em suas relações com os demais, é, talvẹz, o momento mais crítico. Mesmo em uma situação normal sempre há conflitos a serem resolvidos na primeira gravidez. Para a gestante solteira, obviamente, este processo é muito mais difícil. Em adição, ela teme a hostilidade, censura e rejeição da família e da sociedade e, principalmente, teme a reação do namorado.

No estudo, os sentimentos iniciais relatados pelas gestantes adolescentes solteiras ao tomarem consciência da gravidez variaram entre a aflição, o choque, o medo e a dificuldade de aceitação.

Sabendo-se grávidas, as expectativas das adolescentes voltaram-se para os namorados - aqueles que podiam "salvá-las" da exposição de uma gravidez pré-conjugal à censura da familia e da sociedade. Para umas, a esperança é que eles "assumam" a paternidade, não estando explícito $\mathrm{cm}$ seu discurso se o "assumir" envolve casar. Outras vão mais além e começam a fazer pressão sobre o namorado para casar. Há, porém, as que, por preverem uma possível rejeição, sentem medo e afastam-se gradativamente do namorado, preferindo enfrentar a tudo e a todos sozinhas.

Frustradas as expectativas em relação aos namorados, não resta senão aguardar as reações dos familiares e, depois, as reações daqueles que compõem o seu círculo social.

Evidentemente, a gestação pré-conjugal criou, ou acentuou, um quadro distinto de problemas de relacionamento das adolescentes com seus familiares. Observou-se, particularmente, que algumas adolescentes passaram momentos difíceis, temendo que os familiares tomassem conhecimento da gestação e que, em parte, o medo parecia estar relacionado com os sentimentos conflituosos de se terem "perdido", como elas falam.

Segundo OSOFSKY \& OSOFSKY ${ }^{4}$, embora seja uma crença comum, não é apropriado acreditar que os familiares pertencentes a classes sociais economicamente desfavorecidas aceitem mais facilmente a gestução de suas filhas e prontanente assumam a tarefa de criar o neto. Embora possa acontecer, muitos não se comportam desta forma. A raiva parece ser, de início, a resposta parental mais comum. Esta raiva pode ser tão intensa que a jovem sente necessidade de, ou é pressionada para, sair de casa. Acompanhando a raiva há, freqüentemente, sentimentos de vergonha e culpabilidade. Vergonha, em pensar no que dirão os vizinhos e amigos; e culpabilidade, pelo papel que podem ter desempenhado em contribuir para a gravidez. Em qualquer caso, as famílias de gestantes adolescentes solteiras vivenciam um dilema quando as filhas engravidam.

Os relatos das gestantes parecem corroborar a afirmativa destes autores, tanto no que diz respei- 
to à improcedência da crença, quanto com relação às reações familiares. Um aspecto, no entanto, deve ser destacado - dentre os familiares de algumas das gestantes, os elementos do sexo masculino se sentiam mais "desonrados" e mais enraivecidos com a gestação pré-conjugal; as mulheres pareciam mais propensas a se conformarem, a compreenderem e a darem apoio às gestantes, mesmo que, no processo de "aceitação", também passassem por momentos de raiva e vergonha.

Considera-se que estes dois sentimentos predominantes - a raiva e a vergonha - são perfeitamente compreensíveis quando se lembra que "moça de familia só mantém relações sexuais e só engravida depois do casamento". Considera-se, também, compreensível o sentimento de desonra implícito no discurso das adolescentes.

A honra é definida, em sentido objetivo, como um sentimento que leva o indivíduo a procurar merecer e manter a consideração geral. Ou seja, é um sentimento que está incorporado à identidade social do indivíduo e, como tal, precisa ser reforçado pelos outros. A gestante sol ${ }^{+}$.eira, desvian. do-se do comportamento moral-sexual "ideal", põe em risco, além da própria, a identidade social de seus familiares - "é uma puta na familia", é uma "menina que não presta" na família, como afirmaram duas delas.

A não-aceitação de sua permanência em casa, sendo-lhes, inclusive, proibidas as visitas, foi narrada por três das gestantes. Em outros três casos, os familiares, mesmo não se podendo afirmar que tenham se conformado facilmente com a gestação, reagiram de forma mais positiva. Apesar do apoio, é interessante que se note como a família passa a gerenciar as resoluções da gestante, talvez por considerá-la incapacitada para fazê-lo. Essa atitude familiar foi percebida por uma adolescente que, em vista disso, negou-se a confirmar a gravidez à família.

"Meu tio, ele desconfiou, perguntou pra mim. Eu falei: 'Não, não tinha acontecido nada'. Ele falou que, se tivesse acontecido, ele ia me ajudar, sabe? Mas, eu sei que, no fundo, ele ia ficar com a criança, porque eu ainda sou menor, né? Ele acha que eu não posso cuidar. Ele ia ficar com a criança".

Além da rejeição, da vergonha e do gerenciamento das resoluções a serem tomadas, óbservou-se, também, que a gestação em adolescentes solteiras pode despertar na família sentimentos de frustração por não poder mais realizar antigas aspira- ções em relação ao casamento de suas filhas virgens e de branco, como preceitua o código moral e religioso.

Esses valores são transmitidos ao indivíduo, especialmente ao do sexo feminino, desde a mais tenra idade e podem se tornar tão marcantes em sua vida que uma gestante afirmou certa vez: "Você não se admire se, depois desta gravidez, um dia eu cometer um pecado e entrar na Igreja de branco". Compreende-se, assim, o sentido da expres. são "perder-se". Ceder ao impulso sexual antes do casamento, além de desvio moral, significa, também, perder a oportunidade de alcançar o Paraíso, por ter cometido "pecado".

Os demais parentes e as pessoas que compõem o círculo social das adolescentes (amigos e vizinhos) também exercem uma influência decisiva sobre a forma como elas encaram a gravidez e constroem sua auto-imagem, enquanto gestantes solteiras. Em alguns discursos, elas afirmam não se importar com o que "as pessoas falam", e até percebem que essas pessoas desejam apoiá-las; em outros, porém, a revolta está patente.

A gestação pré-conjugal, a despeito do que se possa afirmar em contrário, representa uma agres. são à moral sexual prevalente no Brasil. Isto é particularmente verdadeiro quando ela ocorre em mulheres oriundas de classes sociais economicamente desfavorecidas, como é o caso das adolescentes do estudo.

Já se afirmou, anteriormente, que essa moral sexual é contraditória. Aqui, novamente avulta a contradição: ao mesmo tempo em que se afirma a destinação da mulher à maternidade, a gestante solteira, por não ter aguardado o casamento, é estigmatizada como imoral, pervertida e anti-social. E, como indivíduo "desviante" (VELHO)", padece de sanções - por exemplo, se está empregada, é despedida, e não consegue outro emprego ("grávida, elas não aceita"\%.

A marginalidade social de sua condição é percebida pelas adolescentes do estudo, sendo expressa por sentimentos de inadequação e vergonha, por tentativai de reestruturação da identidade social ameaçada, ou por declarações explícitas sobre o preconceito social que pesa sobre a mãe solteira e que se reflete em sua família.

Mesmo aquelas que afirmavam encarar a sua gravidez como sendo um acontecimento natural terminavam, na continuidade das narrativas, por trair a ambivalência de sentimentos a esse respeito, pois percebiam a discriminação social que pesa so 
bre elas, bem como percebiam as conseqüências práticas dessa discriminação.

Socializadas de acordo com uma moral sexual dúbia, onde o que se proíbe é o que se permite, e o que se permite é o que se proíbe, a consciência da gestação desperta nestas adolescentes um sentimento de terem feito algo errado; de terem quebrado, com seu comportamento, limites e valores de determinada situação socio-cultural; de "estarem perdidas", portanto.

Antevendo a crise familiar, a censura da sociedade, e sujeitas à rejeição dos namorados que não assumem sua parte de responsabilidade no fato $e$ declinam de legitimizar a gravidez aos olhos da sociedade casando com elas, importantes decisões têm que ser tomadas. Das quatro opçð̃es que normalmente elas teriam, uma está obviamente eliminada - casar. Restam, portanto, abortar, levar a gestação a termo e conservar o bebê, ou levar a gestação a termo e entregar o bebê para adoção.

A gestação e a maternidade são eventos muito significativos na vida de uma mulher e, em vista disso, nenhuma resolução que a gestante adolescente solteira tome parece estar isenta de importância.

Manter a criança envolve questões básicas de sobrevivência, já por si sós tão deficitárias, e que podem se agravar, caso esta seja a escolha feita. A decisão de entregar a criança para adoção, logo após seu nascimento, ocorre como um processo extremamente doloroso, com conseqüências emocionais que, provavelmente, perdurarão ao longo de sua existência. A simples tentativa de abortamento, como aconteceu com algumas delas, também traz efeitos negativos, como o medo de que as substâncias ingeridas ou injetadas possam trazer problemas ao desenvolvimento do feto e de, posteriormente, serem ou se sentirem culpadas por isto.

Vale ressaltar que a decisão de assumir a responsabilidade pela criação do filho às vezes tem o significado implícito de um castigo merecido por se ter desviado das normas institucionalizadas:

"Não, não... eu não vou tirar, não. Que é isso, né? Acho que isso é pra gente aprender!"

Tendo em vista o que foi exposto, concorda-se com SILVA ${ }^{5}$ e CLAMAN et alii ${ }^{2}$, quando afirmam ser fácil imaginar o desespero, o medo e a insegurança de uma adolescente ao se saber grávida. Além das manifestações emocionais comuns à vivência de uma primeira gestação, elas se sentem atemorizadas com a perspectiva de criar o filho sem condições de fazê-lo - "Eu tenhomedo de não dar conta de criar, sabe?'; e se sentem atemorizadas com as puniçð̃es que antevêem caindo sobre elas - "Que eles não baldeassem tanto, né?"

Daí o difícil caminho a percorrer na tomada de decisões: em primeiro lugar, são feitas tentativas caseiras para abortar, já que seus parcos recursos não lhes permitem realizar um aborto em clínicas especializadas; depois, tentam elaborar a idéia de entregar o filho para adoção;e, finalmente, acomodam-se à idéia de criar o filho, com uma perspectiva de vida que, muito provavelmente, reproduzirá as suas próprias histórias de vida. Naturalmente, tudo isto é historicamente determinado, inclusive a participação e reação daqueles que se supõe serem os pais das crianças que estavam por nascer.

Durante a fase de estruturação do trabalho, quando se solicitou a uma gestante adolescente sua opinião sobre o tipo de ajuda de que poderia estar necessitando e sobre quem poderia dar esta ajuda, ela expressou-se da seguinte forma: " $E$ alguém faz alguma coisa para ajudar a mãe solteira...?" Em seguida, após refletir um pouco, completou: "Acho que vocês devia chegar no canto e dar um puxão de orelhas!"

A ajuda que as gestantes adolescentes solteiras do estudo julgavam necessária, talvez pela situação hospitalar em que as entrevistas se desenvolveram, ou, quem sabe, por inabilidade em se explorar melhor os aspectos sociais de sua problemática, dizia respeito, quase sempre, a aspectos de conhecimento sobre o mecanismo de parto, de como cuidar da criança, e de assistência à saúde da criança. Uma resposta a este item, entretanto, merece destaque:

"Agora,... acho que não tem nada que as pessoa possa fazer para me ajudar."

\section{CONCLUSÕES}

O conhecimento das representaçð̄es das gestantes adolescentes solteiras sobre fatos e dados que compõem a realidade psicossocial por elas vivenciada permite concluir que:

- $O$ início da atividade sexual e a gestação em adolescentes podem concorrer para um desajuste psicossocial, manifestado no discurso dessas adolescentes, pela ambivalência e/ou contradições no que diz respeito a sexo e a sexualidade, maternidade e valores sociais.

A interpretação das informações obtidas atra- 
vés dos relatos das gestantes adolescentes solteiras permite concluir que:

- Os problemas vivenciados por gestantes adolescentes solteiras dizem respeito, principalmente, às condições em que se dá a socialização e construção da identidade social/ sexual da mulher, e à sua inserção em uma estrutura social que estigmatiza, marginaliza e oprime a mãe solteira, embora afirme a destinação da mulher à maternidade.

GARCIA, T. R. Unmarried pregnant teenagers representations about their psychological problems. Rev. Bras. Enf., Brasília, 38(3/4): 281-288, Jul/Dec. 1985.

\section{REFERÉNCIAS BIBLIOGRAFICAS}

1. CAMPOS, J.C. \& CARVALHO, H.A.G. A mãe solteira. In: Psicologia do desenvolvimento: influência da familia. São Paulo, EDICON, 1981. p. $123-66$

2. CLAMAN, D.A. et alii. Reaction of unmarried girls to pregnancy. Canad. Med. Ass. J., Ottawa, 101: 328-34, sept. 1969.

3. MALDONADO, M.T.P. Psicologia da gravidez, parto e puerpério. Petrópolis, Vozes, 1976. p. 11-7.

4. OSOFSKY, J.D. \& OSOFSKY, H.J. Teenage pregnancy; psychosocial considerations. Clin. Obstet. Gynecol., Hargestown, 21(4):1161-73, dec. 1978.

5. SILVA, J.L.P. Contribuição ao estudo da gravidez no adolescência. Campinas, 1983. 123 p. Tesc (Doutorado) UNICAMP. liaculdade de Ciências Médicas.

6. VALENTE, C.A. et. alii. Assistência pré e perinatal à mãe adolescente. J. Bras. Ginecol., Rio de Janeiro, 83(5):229-35. maio. 1979.

7. VELHO, G. Desvio e divergência; uma crítica da patologia social. Rio de Janeiro, Zahar, 1981. p. 1028. 